\title{
Erratum to: Solutions of Schrodinger equation for the modified Mobius square plus Kratzer potential
}

\author{
C. P. Onyenegecha ${ }^{1, a}$, C. A. Onate ${ }^{2}$, O. K. Echendu ${ }^{1}$, A. A. Ibe ${ }^{3}$, H. Hassanabadi ${ }^{4}$ \\ ${ }^{1}$ Department of Physics, Federal University of Technology, Owerri, Nigeria \\ 2 Department of Physical Sciences, Landmark University, Omu-Aran, PMB 1001 Omu Aran, Kwara, Nigeria \\ ${ }^{3}$ Department of Physics, Nigerian Maritime University, Okerenkoko, Delta State, Nigeria \\ ${ }^{4}$ Department of Physics, Shahrood University of Technology, Shahrood, Iran
}

Published online: 28 April 2020

(c) Società Italiana di Fisica and Springer-Verlag GmbH Germany, part of Springer Nature 2020

\section{Erratum to: Eur. Phys. J. Plus (2020) 135:289 \\ https://doi.org/10.1140/epjp/s13360-020-00304-z}

The article "Solutions of Schrodinger equation for the modified Mobius square plus Kratzer potential", written by C. P. Onyenegecha, C. A. Onate, O. K. Echendu, A. A. Ibe and H. Hassanabadi, was originally published electronically on the publisher's internet portal (currently SpringerLink) on 06 March 2020 with open access. With the author(s)' decision to step back from Open Choice, the copyright of the article changed on 27 April 2020 to (C) Società Italiana di Fisica and Springer-Verlag GmbH Germany, part of Springer Nature 2020 and the article is forthwith distributed under the terms of copyright.

The original article can be found online at https://doi.org/10.1140/epjp/s13360-020-00304-z.

\footnotetext{
a e-mail: chibueze.onyenegecha@ futo.edu.ng (corresponding author)
} 